\title{
Frequency-Force Relationship in Dog Atrial Muscle as Modified by Acetylcholine
}

\author{
Hidehiko Watanabe, Kimiko Kawai and Shigetoshi \\ Chiba \\ Department of Pharmacology, Shinshu University School of \\ Medicine, Matsumoto 390
}

\begin{abstract}
Watanaba, H., Kawai, K. and Chiba, S. Frequency-Force Relationship in Dog Atrial Muscle as Modified by Acetylcholine. Tohoku J. exp. Med., 1982, 136 (1), 75-78 - The effects of acetylcholine on the frequency-force relationship in isolated $\operatorname{dog}$ atria were investigated in a frequency range of $2-3.5 \mathrm{~Hz}$. The atria were suspended in a bath and perfused with arterial blood from a carotid artery of a heparinized donor dog. The frequency-force relationship was uniformly and dose-dependently suppressed by infusion of acetylcholin in 3 different doses at the frequency range of $2-3.5 \mathrm{~Hz}$, and acetylcholine did not induce a negative staircase. - . - isolated $\operatorname{dog}$ atria; frequency-force relationship; acetylcholine
\end{abstract}

Previously Chiba (1977) reported that the developed tension of isolated dog atria was less suppressed by acetylcholine at lower frequencies of stimulation than at higher frequencies. However, the effect of acetylcholine within a physiological range of frequencies such as $2-3.5 \mathrm{~Hz}$ was not examined in detail, although the previous experiments (Chiba 1977) were performed in a wide frequency range from 0.017 to $4 \mathrm{~Hz}$. In the present study, the effect of acetylcholine on the frequency-force relationship within almost the physiologic range of frequencies was precisely examined, using isolated and blood-perfused dog atrial preparations (Chiba et al. 1975a, b).

\section{Methods}

Five adult mongrel dogs weighing from 9 to $15 \mathrm{~kg}$ were anesthetized with sodium pentobarbital $(30 \mathrm{mg} / \mathrm{kg}$, i.v.). The right atrium was removed and immersed in Tyrode solution at $4-10^{\circ} \mathrm{C}$. The isolated atrium was then perfused with arterial blood conducted from the carotid artery of the heparinized donor dog by the aid of a peristaltic pump. It was suspended in an organ bath filled with blood at $37^{\circ} \mathrm{C}$. Atrial rate was measured with a cardio-tachometer, and isometric tension development with a force displacement transducer. The muscle was usually subjected to a tension of $2 \mathrm{~g}$. Perfusion pressure was kept constant at $100 \mathrm{mmHg}$. The details of the preparation are described in previous papers (Chiba et al. 1975a, b). The continuous infusion of acetylcholine was performed by use of an infusion-withdrawal pump (Harvard Apparatus, Model 600-900). The preparation was stimulated electrically through bipolar electrodes sewn to the free atrial wall. Frequency of stimulation was changed, but voltage and duration were fixed (1-3 V, suprathreshold electrical square waves of $1 \mathrm{msec}$ duration).

Received for publication, February 21, 1981. 


\section{Results}

When acetylcholine was administered into the cannulated sinus node artery of the isolated $\operatorname{dog}$ atrium, negative chronotropic and inotropic effects were consistently induced (Chiba et al. 1975a, b; Chiba 1976a). In the preparation which was electrically paced, a continuous infusion of acetylcholine caused a stable depression of the atrial tension development.

The frequency-force relationship was examined in a frequency range of 2-3.5 $\mathrm{Hz}$ with or without an infusion of acetylcholine. In non-treated atria, a stepwise rise of paced frequency produced an enhancement of the developed tension, indicating a positive staircase in this frequency range (Chiba 1976b).

At a relatively small dose level of acetylcholine $(1 \mu \mathrm{g} / \mathrm{min})$, the developed tension was slightly and uniformly suppressed in any paced frequency examined $(2-3.5 \mathrm{~Hz})$. With increasing the dose level $(2 \mu \mathrm{g} / \mathrm{min})$, it was much greatly and uniformly suppressed. At an extremely large dose of $5 \mu \mathrm{g} / \mathrm{min}$, it was markedly suppressed but still positive staircase phenomenon was observed as shown in Fig.

1. Summarized data are shown in Fig. 2.

\section{ISCUSSION}

As reviewed by Koch-Weser and Blinks (1963), a small concentration of acetylcholine which produced little or no inotropic effect at low frequencies in

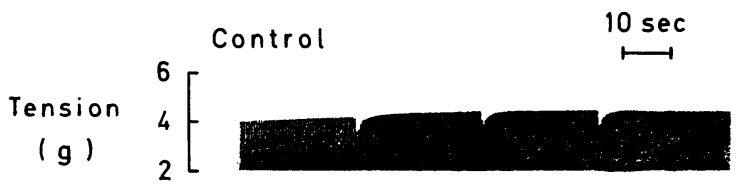

Acetylcholine $(1 \mu \mathrm{g} / \mathrm{min})$
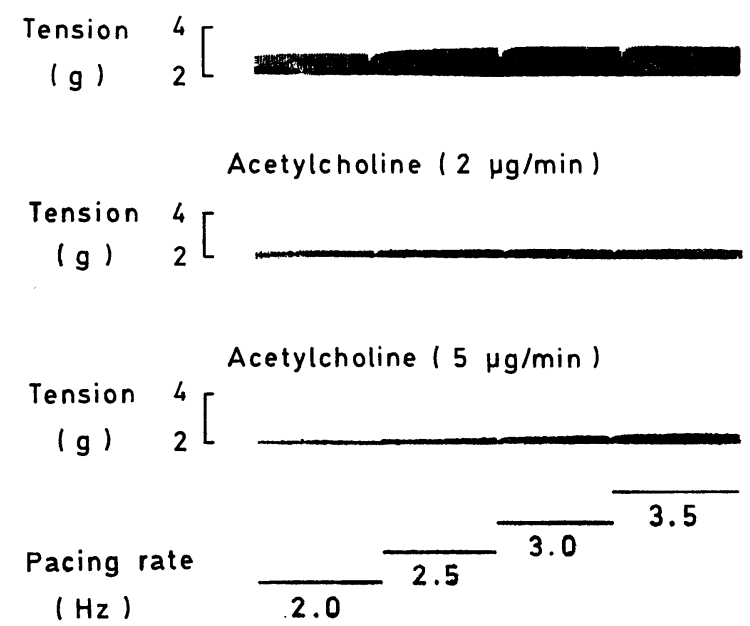

Fig. 1. Effects of a continuous infusion of three different doses of acetylcholine on the frequency-force relationship of an isolated and blood-perfused atrial muscle of the dog. 


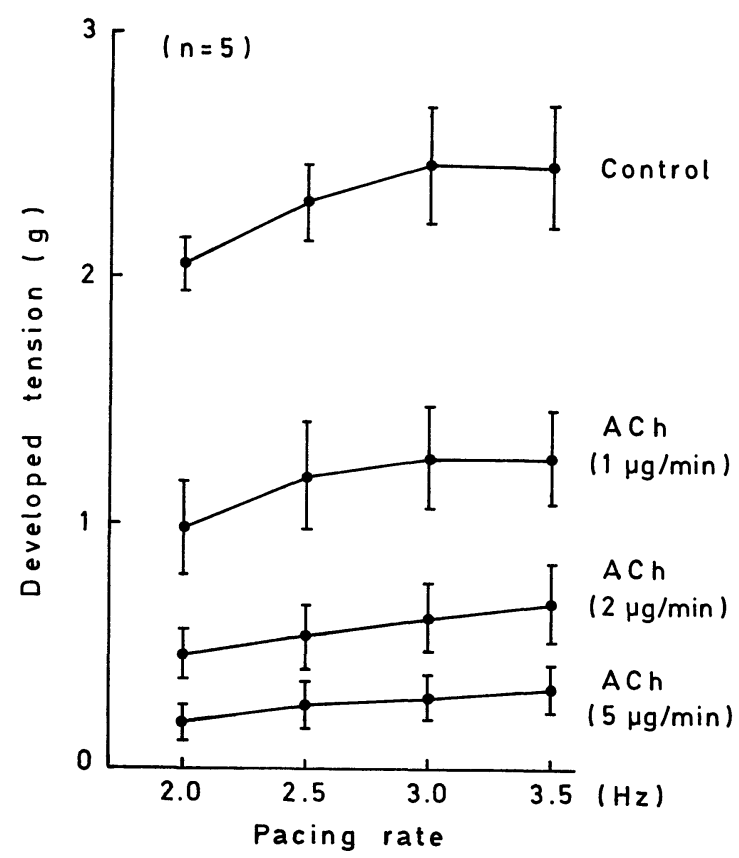

Fig. 2. Steady-state frequency-force relationship of isometrically contracting dog atrial muscle: influence of 1,2 and $5 \mu \mathrm{g} / \mathrm{min}$ of acetylcholine. Vertical bars represent standard errors. Ordinate, tension in $\mathrm{g}$; Abscissa, frequency.

rabbit, rat and cat atria had a marked negative inotropic effect at higher frequencies. In 1967, Friedman et al. also reported that the negative inotropic effect of acetylcholine was more prominent as the frequency of contraction was increased in isolated cat atria. Their results showed that the positive staircase was inverted to the negative one by treatment with $1 \mu \mathrm{g} / \mathrm{ml}$ of acetylcholine at a frequency range of 20-120 beats/min. In the present study by use of dog atrial muscle, no negative staircase was observed in examined frequencies (120-210 beats/min) before and after 3 different concentrations of acetylcholine. The difference between our results and theirs may be not due to difference in species but due to difference in frequency ranges used.

Previously, we showed that a negative staircase phenomenon was readily induced by treatment with calcium-antagonistic drugs, verapamil and nifedipine, in a physiological frequency range of $1.5-3.5 \mathrm{~Hz}$ on canine atrial and ventricular muscles (Chiba 1976b; Chiba et al. 1978a, b). In the present study, infusion of acetylcholine produced uniform suppression of the frequency-force relationship in a physiological frequency range at any examined concentration. Thus, the effect of acetylcholine differs from that of verapamil or nifedipine.

In atrial muscle, it is well known that acetylcholine causes the reduction in action potential duration which will result in a reduced amplitude and duration of contraction. Since the plateau phase of the cardiac action potential could be due 
to an inward calcium current (Grossman and Furchgott 1964; Ikemoto and Goto 1977), the action of acetylcholine might be partially due to inhibition of a slow inward calcium current (Giles and Noble 1976). However, the mechanism of action of acetylcholine on contractility is still not clear and it will be needed to investigate effect of acetylcholine on intra-cellular calcium movement in cardic muscle.

\section{References}

1) Chiba, S. (1976a) Differences in chronotropic and inotropic responses of canine atrial muscle and SA node pacemaker activity to adenosine and ACh. Jap. Heart J., 17, 7379.

2) Chiba, S. (1976b) Effect of pentobarbital, verapamil and manganese on the frequencyforce relationship of the isolated atrium and ventricle of the dog. Europ. J. Pharmacol., 40, 225-232.

3) Chiba, S. (1977) Effects of acetylcholine on the frequency-force relationship of the isolated dog atrium. Clin. exp. Pharmacol. Physiol., 4, 575-577.

4) Chiba, S., Kimura, T. \& Hashimoto, K. (1975a) Muscarinic suppression of the nicotinic action of acetylcholine on the isolated, blood-perfused atrium of the dog. Naunyn-Schmiedeberg's Arch. Pharmacol., 289, 315-325.

5) Chiba, S., Yabuuchi, Y. \& Hashimoto, K. (1975b) Comparison of the effects of norepinephrine and acetylcholine between intraarterial and extravascular administration to the isolated blood-perfused canine atrium. Jap. J. Pharmacol., 25, 433-439.

6) Chiba, S., Furukawa, Y. \& Kobayashi, M. (1978a) Effect of nifedipine on frequencyforce relationship in isolated dog left ventricular muscle. Jap. J. Pharmacol., 28, 783785.

7) Chiba, S., Kobayashi, M. \& Furukawa, Y. (1978b) Effects of optical isomers of verapamil on SA nodal pacemaker activity and contractility of the isolated dog heart. Jap. Heart J., 19, 409-414.

8) Friedman, W.F., Buccino, R.A., Sonnenblick, E.H. \& Braunwald, E. (1967) Effects of frequency of contraction and ionic environment on the responses of heart muscle to acetylcholine. Circul. Res., 21, 573-582.

9) Giles, W. \& Noble, S.J. (1976) Changes in membrane currents in bullfrog atrium produced by acetylcholine. J. Physiol., 261, 103-123.

10) Grossman, A. \& Furchgott, R.F. (1964) The effects of various drugs on calcium exchange in the isolated guinea-pig left auricle. J. Pharmacol. exp. Ther., 145, 162172.

11) Ikemoto, Y. \& Goto, M. (1977) Effects of ACh on slow inward current and tension components of the bullfrog atrium. J. mol. cell. Cardiol., 9, 313-326.

12) Koch-Weser, J. \& Blinks, J.R. (1963) The influence of the interval between beats on myocardial contractility. Pharmacol. Rev., 15, 601-652. 